\title{
Strategi Komunikasi untuk Meningkatkan Partisipasi Masyarakat Pesisir dalam Pembudayaan GERMAS di Kecamatan Kalianget
}

\author{
Oleh: \\ Roos Yuliastina ${ }^{1)}$, Nailiy Huzaimah ${ }^{2)}$, Isyanto $^{3)}$ \\ Fisip Universitas Wiraraja ${ }^{1)}$, FIK Universitas \\ Wiraraja $^{2)}$, FEB Universitas Wiraraja ${ }^{3)}$ \\ Email:tina.fisip@wiraraja.ac.id.
}

\begin{abstract}
Abstrak
Kabupaten Sumenep dapat memberikan kontribusi positif sebagai salah satu daerah pengasil tangkapan hasil laut dan penghasil garam di tingkat Nasional. Berdasarkan data BPS kabupaten Sumenep dalam setahun dapat menghasilkan 532 ton ikan laut per tahun dan tiap tahunnya dapat menghasilkan 286.42 ton garam dari kecamatan Kalianget untuk memenuhi pasokan garam Nasional (BPS, 2018). Selain manfaat positif yang dijelaskan diatas, kondisi goegrafis kabupaten Sumenep yang berada di kawasan pesisir tidak lepas dari masalah sosial, ekonomi, dan kesehatan masyarakat pesisir yang identik dengan ketertinggalan dan keterbelakangan. Selain masalah ekonomi seperti penghasilan petani garam yang rendah, masalah lain seperti masalah prilaku hidup bersih, sanitasi, buang air besar sembarangan (BABS) kebersihan lingkungan, dan hipertensi menjadi permasalahan utama. Sedangkan program edukasi seperti sosialisasi dari Promkes Puskesmas Kalianget, bantuan tempat sampah dan truk pengangkut sampah, pembangunan MCK komunal, bahkan membentuk kelompok sadar sampah (POKDARSA) nyatanya belum mampu membuat tiga desa ini beranjak dari permasalahan kebersihan lingkungan. Penelitian ini ingin menjawab permasalahan masyarakat pesisir dari aspek komunikasi melalui pendekatan Fenomenologi, karena untuk menciptakan komunikasi yang efektif perlu adanya penelitian yang komprehensif, maka terlebih dahulu mengumpulkan data terkait prilaku kesehatan masyarakat setempat. Hasil pengumpulan data terkait prilaku kesehatan masyarakat akan menjadi modal awal untuk memetakan strategi komunikasii untuk meningkatkan partisipasi pembudayaan gerakan sehat di masyarakat pesisir khususnya di tiga desa kecamatan Kalianget.
\end{abstract}

Kata Kunci : Strategi Komunikasi, Partisipasi masyarakat pesisir, dan GERMAS

\begin{abstract}
As one of the coastal areas, Sumenep district can make a positive contribution as one of the marine catchment areas and salt producers at the national level. Based on BPS data, Sumenep district can produce 532 tons of marine fish per year and every year it can produce 286.42 tons of salt from Kalianget sub-district to meet the national salt supply (BPS, 2018). In addition to the positive benefits described above, the geographical condition of Sumenep Regency which is located in the coastal area cannot be separated from the social, economic, and health problems of coastal communities which are identical with backwardness and backwardness. In addition to economic problems such as the low income of salt farmers, other problems such as clean living behavior, sanitation, open defecation (BABS), environmental hygiene, and hypertension are the main problems. Meanwhile, educational programs such as socialization from the Kalianget Health Center Promkes, assistance with garbage bins and garbage trucks, the construction of communal toilets, and even forming a waste awareness group (POKDARSA) have in fact not been able to make these three villages
\end{abstract}


move away from environmental hygiene problems. from the aspect of communication through a phenomenological approach, because to create effective communication there needs to be a comprehensive research, then first collect data related to the health behavior of the local community. The results of data collection related to public health behavior will be the initial capital to map out communication strategies to increase participation in the cultivation of healthy movements in coastal communities, especially in the three villages of Kalianget subdistrict.

Keywords: Communication Strategy, Coastal Community Participation, and GERMAS

\section{PENDAHULUAN}

Kabupaten Sumenep menjadi salah satu kabupaten di pulau Madura yang memiliki kawasan pesisir pantai sepanjang $577,76 \mathrm{~km}$. Wilayah pesisir di kabupaten Sumenep terbagi menjadi dua bagian, wilayah pesisir darat dan pesisir kepulauan. Pesisir kepulauan di kabupaten Sumenep terdiri dari 126 pulau, dengan rincian sebanyak 48 Pulau yang berpenghuni dan 78 pulau yang tidak berpenghuni. Kawasan wilayah pesisir darat terbagi menjadi dua kelompok yaitu (1) kelompok masyarakat pesisir nelayan dan (2) kelompok petani garam. Basis kelompok masyarakat pesisir nelayan tersebar di kecamatan Pasong - songan, Dungkek, Gapura, Batang - batang dan Dasuk. Sedangkan basis wilayah pesisir penghasil garam berada di kecamatan Gapura Desa Gersik putih dan kecamatan Kalianget desa Marengan laok, Karanganyar dan Pinggir Papas (http://dataprimer.sumenepkab.go.id.).

Sebagai salah satu wilayah pesisir, kabupaten Sumenep dapat memberikan kontribusi positif sebagai salah satu daerah pengasil tangkapan hasil laut dan penghasil garam di tingkat Nasional. Berdasarkan data BPS kabupaten Sumenep dalam setahun dapat menghasilkan 532 ton ikan laut per tahun dan tiap tahunnya dapat menghasilkan 286.42 ton garam dari kecamatan Kalianget untuk memenuhi pasokan garam Nasional (BPS, 2018).

Selain manfaat positif yang dijelaskan diatas, kondisi goegrafis kabupaten Sumenep yang berada di kawasan pesisir tidak lepas dari masalah sosial, ekonomi, dan kesehatan masyarakat pesisir yang identik dengan ketertinggalan dan keterbelakangan. Masyarakat Pesisir seperti nelayan dan petani garam masih terbelit oleh persoalan kemiskinan dan keterbelakangan. Terdapat persoalan ter tentu terkait dengan aspek ekologis, sosial, dan ekonomi, sehingga masyarakat pesisir masih tertinggal, Rendahnya taraf hidup masyarakat pesisir dan akses yang terbatas akan aset dan sumber-sumber pembiayaan bagi nelayan kecilmerupakan persoalan utama yang dijumpai di kawasan pesisir (Amanah, 2010).

Kemiskinan dan ketertinggalan menjadi fenomena klasik yang harus di 
hadapi oleh masyarakat pesisir seperti nelayan dan petani garam. Terdapat beberapa hasil penelitian tentang masyarakat pesisir yang menunjukkan bahwa kemiskinan pada nelayan dan petani garam diantaranya dikarenakan kondisi ekosistem yang keras, dan sumber kehidupan yang bergantung pada pemanfaatan sumber daya pesisir dan laut, akses yang terbatas akan aset dan sumbersumber pembiayaan bagi nelayan kecil merupakan persoalan utama yang dijumpai di kawasan pesisir. Nelayan pun sangat rentan terhadap tekanan pemilik modal(Amanah, 2010).

Kondisi demikian juga tidak berbeda jauh kondisi petani garam, kemiskinan dan keterbelakangan pada petani garam pada umumnya disebabkan oleh eksploitasi, alienasi, dan tata niaga garam rakyat namun saat ini kemiskinan yang petani garam alami telah berkembang menjadi sebuah bentuk kemiskinan yang bukan hanya mengalami kekurangan dalam pemenuhan kebutuhan.

Pendapat diatas berbanding lurus dengan kondisi masyarakat pesisir di kabupaten Sumenep, khususnya pada daerah basis petani garam di tiga desa kecamatan Kalianget, yaitu desa Marengan Laok, Karanganyar dan Pinggir Papas sebagai desa penghasil garam di Kabupaten Sumenep. Berdasarkan hasil wawancara dengan masyarakat setempat bahwa faktor latar belakang pendidikan, ekonomi dan sosial budaya masyarakat pesisir di kecamatan Kalianget berpengaruh terhadap prilaku keseharian masyarakat setempat. Faktor rendahnya tingkat pendidikan, pengetahuan, dan pendapatan masyarakat setampat berdampak terhadap prilaku masyarakat sehari - hari, hal ini dapat dilihat dari kondisi lingkungan pesisir yang tidak bersih.

Berdasarkan data hasil penelitian sebelumnya di desa Karanganyar dan Pinggir papas secara umum tingkat pendidikan masyarakat setampat berpendidikan rendah (lulus SD dan SMP) sebanyak 94,0 \%, Setingkat SMA dan D3 sebanyak $6,0 \%$. Tingkat pendidikan ternyata berkaitan dengan kasadaran masyarakat dalam memanfaatkan sanitasi umum dan menerapkan prilaku hidup bersih dan sehat. Untuk desa Pinggirpapas ini telah ada fasilitas MCK umum, sudah bangun di 3 Dusun yaitu Dusun Kauman, Dusun Ageng, Dusun Dhalem yang tidak dimanfaatkan dengan baik (Sayuti, 2021).

Prilaku masyarakat di Desa Pinggirpapas cenderung tidak ramah lingkungan karena dibentuk oleh kebiasaan yang sudah turun temurun, Kemudian dipengaruhi oleh lemahnya pengawasan akibat tidak adanya regulasi dalam hal ini (Rahmanto \& Suwandi, 2019) 
Selain masalah ekonomi seperti penghasilan petani garam yang rendah, masalah lain seperti masalah prilaku hidup bersih, sanitasi, buang air besar sembarangan (BABS) kebersihan lingkungan, dan hipertensi menjadi permasalahan utama. Permasalahan prioritas masyarakat dari aspek kesehatan masyarakat pesisir di tiga desa, yakni desa Marengan Laok, Karanganyar dan Pinggir Papas menurut penanggung jawab promosi kesehatan (promkes) Puskesmas Kecamatan Kalianget diantaranya; (1) Rendahnya kesadaran prilaku hidup bersih dan sehat (PHBS), (2) Tidak percaya akan Covid - 19, (3) Tingginya penderita Hipertensi.

Masalah PHBS dan kebersihan lingkungan menjadi masalah yang belum bisa dislesaikan sampai saat ini di tiga desa tersebut. Kita ketahui bersama bahwa, program - program kesehatan dari pemerintah pusat, seperti sosialisasi kebersihan lingkungan, bantuan pembangunan sanitasi umum, bantuan Bak sampah dan truk pengangkut sampah dari Dinas Lingkungan Hidup, Bank sampah, pembentukan kelompok Sadar Sampah (POKDARSA) di desa Karanganyar, kegiatan promosi kesehatan yang dilakukan oleh tim Promkes kecamatan Kalianget, baik secara luring dan penyediaan saran informasi kesehatan berbasis media sosial (Facebook dan
Instagram), nyatanya belum mampu membuat masyarakat desa Marengan Laok, Karanganyar dan Pinggir papas merubah sikap dan menerapkan prilaku hidup sehat dan bersih.

Berdasarkan pemaparan diatas dapat diketahui jika, permasalahan rendahnya penerapan prilaku hidup bersih dan sehat masih menjadi masalah yang belum terselesaikan khususnya di tiga desa di kecamatan Kalianget sebagai kawasan basis tambak garam. Sedangkan program edukasi seperti sosialisasi dari Promkes Puskesmas Kalianget, bantuan tempat sampah dan truk pengangkut sampah, pembangunan MCK komunal, bahkan membentuk kelompok sadar sampah (POKDARSA) nyatanya belum mampu membuat tiga desa ini beranjak dari permasalahan kebersihan lingkungan karena masih melakukan buang sampah sembarangan, BABS dan , dan pola hidup tidak sehat karena konsumsi garam tinggi sehingga masyarakat setempat menderita Hipertensi.

Penelitian ini ingin menjawab permasalahan masyarakat pesisir dari aspek komunikasi, $\mathrm{n}$ untuk menciptakan komunikasi yang efektif perlu adanya penelitian yang komprehensif, maka terlebih dahulu mengumpulkan data terkait prilaku kesehatan masyarakat setempat. Hasil pengumpulan data terkait prilaku kesehatan masyarakat akan menjadi modal 
awal untuk memetakan strategi komunikasii untuk meningkatkan partisipasi pembudayaan gerakan sehat di masyarakat pesisir khsusnya di tiga desa kecamatan Kalianget.

\section{Persepetif komunikasi menjadi} penting, karna pada dasarnya kegiatan dan program yang telah berlangsung melalui proses edukasi, sosialisasi luring dan daring (media sosial online), bantuan pembangunan MCK umum menjadi tidak efektif diterima oleh masyarakat setempat. Sehingga perlu di tinjau lebih dalam bagaimana proses strategi dan penyampaian pesan - pesan kesehatan khususnya dalam pembudayaan prilaku hidup bersih dan sehat, sebagaimana program Kementrian kesehatan tentang Pembudayaan gerakan masyarakat sehat (GERMAS) yang tertuang dalam Rencana Startegis Kemnkes tahun 2020 - 2024. Dimana posisi pembudayaan hidup sehat melalui lingkungan yang bersih menjadi tiga program prioritas.

\section{Tujuan Strategis (TS) Kemenkes (2020-2024)}

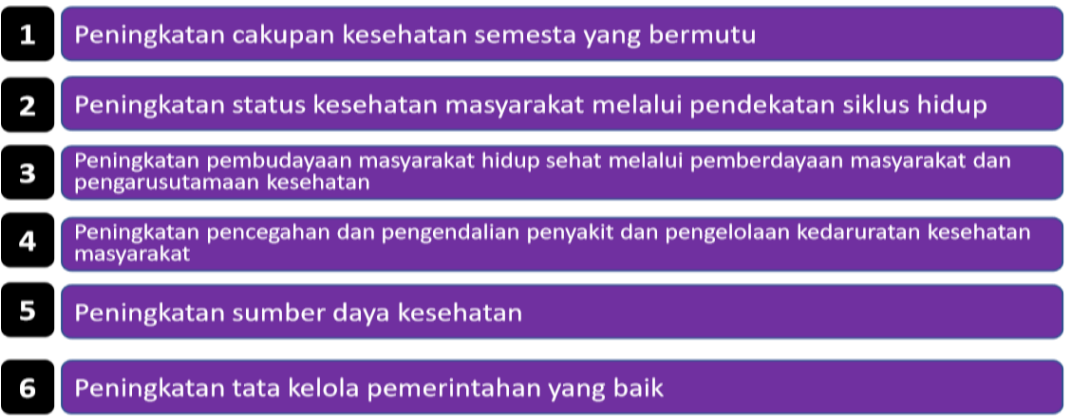

Sumber : (Kemenkes RI, 2020)

Aspek Komunikasi menjadi sangat penting untuk menjawab permasalahan ini. Karena program yang telah di realisaikan untuk meningkatkan kesadaran dan meningkatkan prilaku hidup sehat dan bersih berjalan secara efektif kepada masyarakat setempat. Butuh perencanaan komunikasi dan strategi komunikasi yang mantab antara komunikator dengan komunikan agar pesan yang ingin disampaikan dapat diterima dengan baik. Karena tanpa strategi komunikasi yang baik dan benar, pesan pesan kesehatan, program - program pembangunan di desa tersebut tidak akan menjadi optimal.

Strategi komunikasi menjadi kombinasi yang terbaik dari semua elemen komunikasi dari komunikator, pesan, 
saluran penerima sampai pada pengaruh (efek) yang dirancang untuk mencapai tujuan komunikasi optimal. Pemilihan strategi merupakan langkah krusial yang memerlukan penanganan secara hati-hati dalam perencanaan komunikasi, sebab jika pemilihan strategi salah maka hasil yg diperoleh bisa fatal, terutama kerugian dari segi waktu, materi, dan tenaga (Wijaya, 2015).

Melalui penelitian ini, diharapkan dapat menghasilkan kajian terkait strategi komunikasi yang efektif untuk meningkatkan partisipasi masyarakat pesisir di tiga desa tersebut, partisipasi masyakarakat secara aktif perlu di stimulus melalui kegiatan komunikasi efektif untuk mewujudkan masyarakat yang berbudaya hidup bersih dan sehat.

\section{TINJAUAN TEORITIS}

Adapun state of the art penelitian ini berangkat dari hasil penelitian sebelumnya, bahwa penelitian dengan teori srategi komunikasi lebih dominan di kaitkan dengan teori pembangunan, teori politik dan teori pemerintah. Sedangkan penelitian terdahulu yang dilakukan pada lokus yang sama dengan penelitian ini, yaitu di kecamatan Kalianget desa Pinggir Papas mengkaji tentang persepsi masyarakat dan perencanaan pembangunan MCK komunal bukan dari perseptif prilaku kesehatan masyarakat setempat.
Kebaruan penelitian ini, (1) mengambil dari persepktif dan kajian teori komunikasi, (2) startegi komunikasi untuk meningkatkan partisispasi masyarakat setempat terhadap program pembudayaan GERMAS, sumber informasi yang selama ini digunakan oleh kelompok masyarakat pesisir (petani garam) di desa Marengan laok, Karanganyar dan Pinggir papas kecamatan Kalianget. Dengan demikian alur penelitian ini menyampikan data lebih komprehensif terkait meningkatkan partispasi masyarakat pesisir dalam mewujudkan gerakan masyarakat sehat(GERMAS).

\section{METODE PENELITIAN}

Metode penelitian yang akan digunakan kualitatif. kualitatif merupakan metode penelitian untuk mengekplorasi dan memahami makna yang -oleh sejumlah individu atau kelompok orang- dianggap berasal dari masalah sosial atau kemanusian (Jhon W Creswell, 2017). Pendekatan dalam penelitian ini menggunakan pendekatan Fenomenologi, dimana tujuan penelitian ini menggunakan pendekatan Fenomenologi untuk menggambarkan pengalaman hidup 
kelompok tertentu, yaitu kelompok masyarakat pesisir dari desa Marengan Laok, Karanganyar dan Pinggir Papas yang mayoritas sebagai petani garam terkait komunikasi dan prilaku kesehatan mereka.

Dalam memperoleh data, terdapat tekhnik pengumpulan data yang diambil, yakni pengumpulan data primer dan pengumpulan data skunder dengan teknik purposive sampling.

Peneliti menggunakan teknik analisis data kualitatif. Peneliti menggunakan teknik ini karena data yang terkumpul berupa data-data kualitatif berupa katakata, kalimat atau narasi. Dapat dikatakan bahwa peneliti memulai menganalisis data yang diperoleh sejak hari pertama menapakkan kaki penelitiannya.

Validitas data dalam penelitian ini menggunakan tringulasi. Dari empat macam teknik triangulasi yaitu: triangulasi data, triangulasi peneliti, triangulasi metodologi, dan triangulasi teoritis. Peneliti menggunakan triangulasi data (triangulasi sumber).

\section{HASIL DAN PEMBAHASAN}

\section{Analisis Permasalahan kesehatan Masyarakat Pesisir}

Berdasarkan kegiatan wawancara dan yang telah dilakukan dengan para informan, secara umum para informan memiliki persepsi bahwa telah menerapkan prilaku bersih dan sehat, sesuai kebiasaan dari para orang tua terdahulu. Terkait arti sehat sendiri, baik para informan dari desa Marengan Laok, Karanganyar dan Pinggir Papas beranggapan bahwa sehat adalah sebatas tidak sakit. Terkait kondisi lingkungan di sekitar tambak garam dengan kondisi perumahan padat penduduk, para informan dari perwakilan desa mengatakan bahwa hal tersebut telah menjadi kebiasaan masyarakat sekitar, namun yang terpenting baginya secara individu dan keluarga terdekat tetap diberikan kesehatan meskipun dikesitar lingkungan mereka tinggal permasalahan sampah, minimnya ketersediaan sanitasi dan MCK masih menjadi permasalahan utama masyarakat pesisir tambak garam di Kalianget. Sebelum membahas ke tahap strategi komunikasi terlebih dahulu menganalisis perilaku masyarakat pesisir di desa Marengan Laok, desa Karanganyar, dan Pinggir Papas, khsusnya perilaku dalam pembudayaan GERMAS.

Analisis Perilaku yang dimaksud (Harahap dan Putra; 2019) adalah, bagaimana prilaku seseorang yang berkaitan dengan 
kesehatan dibentuk oleh peristiwaperistiwa dan reaksi-reaksi(anteseden dan konsekuensi) dalam lingkungan sosial maupun lingkungan fisik. Berdasarkan hasil pengumpulan data dapat diketahui jika, permasalahan kesehatan yang dihadapi oleh masyarakat pesisir Kalianget seperti ISPA, penyakit kulit, batuk, hipertensi, diare, bahkan gizi buruk dan rendahnya PHBS menjadi 10penyakit utama di daerah tersebut, dari prilaku masyarakat sendiri yang enggan menerapkan prilaku hidup bersih dan sehat karena mengaggap bahwa kebiasaan sehari-hari seperti, membuang sampah di sungai atau dilaut, membakar sampah, merokok, tidak cuci tangan menggunakan sabun, $\mathrm{BAB}$ sembarangan tidak berpengaruh terhadap kondisi kesehatan mereka.

\section{Elemen Komunikasi Dalam} Penentuan Strategi Komunikasi Dalam Meningkatkan Partisipasi Pembudayaan GERMAS

Penentuan strategi komunikasi yang akan digunakan dalam riset ini menggunakan teori Harold D. Lasswell dengan terlebh dahulu menjawab pertanyaan sebagai berikut: Who Says What In Which Channel To Whom With What Effect. Teori ini menjelaskan tentang eleman - elemen Komunikasi diantaranya: Komunikator, komunikan, media, pesan, dan efek (dampak), (Wijaya,2015).

Elemen $\quad-\quad$ elemen komunikasi ini akan dijabarkan berdasarkan hasil wawancara dari para informan penelitian, yaitu perwakilan masyatakat dari desa Marengan Laok, desa Karanganyar dan desa Pinggir papas.

\section{Komunikator}

Komunikator memiliki peran penting dalam suksesnya pesan komunikasi dapat diterima oleh komunikan. Menurut (Wijaya, 2015)Ada kriteria atau syaratyang harus dimiliki seorang komunikator; memiliki kredibilitas, memiliki daya tarik, dan kekuatan. Artinya komunikator harus memiliki beberapa kriteria agar pesan yang disampikan dapat diterima dan menggungah penerimanya untuk sepemahaman dengan pesan tersebut. Kriteria komunikator yang efektif diantaranya,terampil

berkomunikasi, kaya ide, serta penuh daya kreativitas.

Jika dikaitkan dengan hal tersebut, dapat diketahui bahwa kategori komunikator yang dianggap ideal dan efektif dalam menyampikan pesan - pesan kesehatan khususya pembudidayaan 
Gerakan Masyarakat Sehat di lingkungan pesisir adalah dari golongan tokoh agama, dan tenaga media seperti dokter dan bidan setempat.

Adapun hal tersebut, menjadi pilihan masyarakat dari tiga desa karena alasan yang beragam. Informan dari desa Pinggir papas menyampaikan bahwa menjadi lebih senang dan termotivasi menerima pesan dari tokoh agama atau Kyai atau Ustad setempat. Adapun jawaban lain dari informan di desa Karanganyar dan desa Marengan laok merasa termotivasi dan percaya jika komunikator kesehatan adalah pihak tenaga medis, seperti dokter, bidan desa atau

Terkait perbedaan pemilihan ini, dapat diketahui bahwa masyarakat Pinggir papas merasa lebih percaya dan termotivasi ketika melibatkan tokoh agama yng dekat dengan masyarakat setempat dan mengaitkan kepatuhan menjaga kebersihan kesehatan dengan hadist atau ayat -ayat dalam Islam. Sebagaimana hasilwawancara berikut;

"Sebenarnya sulit untuk percaya ke siapa itu sulit, sekarang ada kabar yang baik tapi nanti ada kabar buruk. Jadi sulit untuk percaya ke siapa-siapa. Apalagi sekarang media sosial macamamacam. Lebih percaya ke tokoh agama soalnya kan ada haditshadits" (Sumber: Yusuf buruh tani garam desa Pinggir Papas).
"Personal, lebih percaya ke tokoh yang ahli di bidang kesehatan yang tahu terkait masalah" (Sumber : Sahirudin buruh tani garam dari desa Marengan Laok).

\section{Komunikan}

Komunikan dalam hal ini adalah masyarakat atau khalayak, dalam studi komunikasi ini disebut juga komunikan. Memahami karakteristik masyarakat khususnya masyarakat pesisir sebagai target sasaran program komunikasi merupakan hal yang sangat penting, sebab semua aktivitas komunikasi diarahkan kepada mereka (Wijaya, 2015).

Terkait karekteristik perilaku masyarakat pesisir di kecamatan Kalianget berdasarkan hasil penelitian sebelumnya bahwa permasalahan kesehatan dan peningkatan keasadaran masyarakat pesisir dapat di kategorikan ke dalam permasalahan defisit kinerja. Yaitu, masyarakat pesisir yang menjadi sudah mengetahui atau pernah mendapatkaninformasi tentang kesehatan tetapi mereka masih belum menjalankan prilaku tersebut dalam kehidupan sehari hari(Yuliastina, 2020). Berdasarkan hal tesebut dapat diketahui bahwa 
karekteristik masyarakat pesisir yang menjadi sasaran dari penyampaian pesan komunikasi kesehatan masih memiliki partisipasi yang rendah untuk menerapkan perilaku bersih atau menerapkan gerakan hidup sehat.

Adapun kondisi masyarakat dalam menerapkan gerakan hidup sehat masih terkendala dengan kondisi lingkungan (luas lahan untuk menanam sayuran, sanitasi dan kesediaan air bersih), pendidikan, dan ekonomi (pendapatan masyarakat sangat bergantung pada cuaca dan sebagian besar penduduk bekerja sebagai tenaga kasar).

\section{Pesan}

Pesan komunikasi dalam hal ini berkaitan dengan pesan kesehatan yang diterima oleh komunikan, baik pesan melalui media massa atau pesan dari orang lain. Masyarakat pesisir di desa Marengan laok, Karanganyar dan Pinggir papas dapat menerima pesan kesehatan secara baik. Terkait dengan pesan gerakan masyarakat sehat (Germas) lebih mengarah pada menjaga kondisi dengan protokol kesehatan $3 \mathrm{M}$ atau $5 \mathrm{M}$, gejala dan penularan covid, vaksinasi, Pemberlakuan Pembatasan Kegiatan Masyarakat (PPKM) karena masa pandemi. Adapun pesan yang diterima khsusnya terkait dengan Germas belum mampu sepenuhnya dimengerti dan prilaku masyarakat pesisir yang menerima pesan tersebut. sebagaimana hasil 89 | Jurnal Public Corner Fisip Universitas Wiraraja wawancara berikut :

"Ada yang mengerti dan ada yang tidak mengerti, kadang informasi yang disampaikan di TV ataupun media sosial menggunakan bahasa kesehatan yang kurang dimengerti"'(Sumber Nadiroh Zulfa mahasiswi dari desa Karanganyar).

“ Sekarang kan sedang Covid, jadi taunya pesan tentang bagaimana peningkatan atau penuruna jumlah covid, untuk mengatahui apakah kita terlalu sering keluar baik atau tidaknya. Pesan harus mematuhi $5 \mathrm{M}$ pastinya, (Sumber Ibu rumah tangga desa Marengan Laok).

"Kalau lebih paham ya dari sosialisasi desa secara langsung kalau melalui media masih kurang, karena saya jarang dirumah karena sering berada di tambak, disuruh diam dirumah dan tentang suruh menjaga kesehatan selama pandemi dengan menggunakan masker," (Sumber Bayu buruh tani garam desa Pinggir papas).

\section{Media komunikasi}

Berdasarkan

hasil pengumpulan data menunjukkan bahwa masayarakat dari desa Marengan laok, Karanganyar, dan Pinggir papas lebih banyak mengetahui informasi kesehatan seperti gerakan masyarakat sehat khusunya di masa pandemi melalui 
televisi seperti iklan dan berita nasional, acara kemasyarakat seperti arisan, pengajian atau kompolan (perkumpulan kelompok) secara tatap muka, dan yang terakhir melalui media sosial seperti youtube.

"Kalau lebih paham ya dari sosialisasi desa secara langsung kalau melalui media masih kurang, karena saya jarang dirumah karena sering berada di tambak," (Sumber Bayu buruh tani garam desa Pinggir papas).

"Saya pake HPnut ninut (tidak bisa akses interner) tidak tau FB, tidak tau apa, dari TV, dari dikasik tau anak juga, dari orang-orang juga, ada kumpulan RT," (sumber Ibu Sitiyani ibu rumah tangga desa pinggir papas)

"Langsung liat di TV tapi kalo di HP biasanya langsung liat di youtube, iya, kalo youtube kan caranya lebih gampang dari pada facebook, kalau facebook kan masih ada kayak fitur-fitur yang belum mengerti," (Sumber Suryani ibu rumah tangga desa Karanganyar).

\section{Efek atau Dampak}

Pada elemen terakhir ini, adalah efek atau dampak yang diperoleh setelah khalayak menerima pesan. Karena semua program komunikasi yang dilakukan pasti memiliki tujuan, yakni mempengaruhi target sasaran. Pengaruh yag diharapkan bisa terjadi dalam bentuk perubahan pengetahuan, sikap, dan prilaku(Wijaya, 90 | Jurnal Public Corner Fisip Universitas Wiraraja
2015). Berdasarkan hasil wawancara yang dilakukan di tiga desa di kecamatan Kalianget dapat diketahui bahwa, pesan pesan komunikasi kesehatan khusunya pesan Gerakan Masyarakat Sehat belum sampai pada perubahan perilaku hanya sampai pada tahapan menambah wawasan atau pengetahuan si komunikan.

"Tidak seratus persen mengubah tapi ada sedikitsedikit pandangan terkait hal itu dikarenakan difilter lagi. Seperti saat ini beritaberita buruk dapat mempengaruhi pikiran masyarakat. Seperti yang awalnya mau divaksin ternyata tidak mau" (Sumber Bayu Ufi Santika Dewi, Ibu rumah tangga desa Marengan Laok).

"Tidak ada, karna masyarakat seperti saya ya masih kurang paham tentang kesehatan. Kalau kesehatan kita kembali lagi sama yang diatas" (Sumber Suyoni buruh petani garam desa Pinggir Papas).

\subsection{Strategi KomunikaStrategi Komunikasi Dalam} Meningkatkan Partisipasi PembudayaanGERMAS

Strategi komunikasi dalam hal penelitian ini berkaitan dengan strategi komunikasi untuk 
meningkatkan partisipasi dalam perpesktif pembangunan pembudayaan Gerakan Masyarakat Sehat masyarakat pesisir.

Terdapat beberapa strategi komunikasi yang mencerminkan suatu rangkaian prioritas tertentu untuk mencapai kebutuhan- kebutuhan pembangunan, diantaranya : (1) Strategi Berdasarkan Media, para komunikator yang menggunakan strategi ini biasanya mengelompokkan kegiatan mereka disekitar medium tertentu yang mereka sukai. (2) Strategi desain instruksional, strategi kelompok ini mendasarkan diri pada teori-teori belajar formal, dan berfokus pada pendekatan sistem untuk pengembangan bahan-bahan belajar.(3) Strategi partisipasi, dalam strategi ini lebih pada prinsip-prinsip penting dalam mengorganisasi dan menekankan kegiatan kerjasama komunitas dan pertumbuhan pribadi (Wijaya, 2015).

Berdasarkan teori diatas jika dikaitkan dalam penelitian ini akan merekomendasikan pada strategi komunikasi pasrtispasi dengan melibatkan kerjasama komunitas didalam lingkungan masyarakat pesisir di kecamatan Kalianget. Diantarnya penguatan GERMAS ini memerlukan sinergisitas antara seluruh lembaga dan atau komunitas sehingga pengalaman ke ikut sertaan dari masing- masing perwakilan dalam proses kegiatan yang menambah pengetahuan dan keterampilan masyarakat setempat.

\section{PENUTUP}

Berdasarkan

analisis

perilaku kesehatan masyarakat pesisir di tiga desa kecamatan Kalianget yaitu desa Marengan Laok, Karanganyar dan Pinggir papas, masyarakat di desa tersebut masuk dalam kategori atau berada pada level Defisit kinerja, artinya masyarakat pesisir sudah mengetahui atau mendapatkan informasi tentang Gerakan Masyarakat Sehat, tetapi mereka masih belum menjalankan prilaku tersebut dalam kehidupan sehari hari. Adapun strategi komunikasi kesehatan yang dapat digunakan untuk meningkatkan partisipasi masyarakat setempat terhadap Gerakan Hidup Sehat dari hasil penelitian ini;

1. Elemen Komunikator: Kategori komunikator yang dianggap ideal dan efektif dalam menyampikan pesan - pesan kesehatan khususya pembudayaan Gerakan Masyarakat Sehat di lingkungan pesisir adalah dari golongan tokoh agama, dan tenaga media seperti dokter dan bidan setempat. Urutan utama yang 
menjadi pilihan informan sebagai komunikator adalah tokoh agamaatau Kyai atau Ustad setempat. Adapun jawaban lain dari informan di desa Karanganyar dan desa merasa lebih percaya dan termotivasi ketika melibatkan tokoh agama yng dekat dengan masyarakat setempat dan mengaitkan kepatuhan menjaga kebersihan kesehatan dengan hadist atau ayat -ayat dalam Islam.

2. Elemen Komunikan: Masyarakat pesisir sudah mengetahui atau mendapatkan informasi tentang Gerakan Masyarakat Sehat, tetapi mereka masih belum menjalankan prilaku tersebut dalam kehidupan sehari -hari. Hal ini berkaitan dengan latar belakang pendidikan, sosial dan ekonomi masyarakat setempat. Adapun kondisi masyarakat dalam menerapkan gerakan hidup sehat masih terkendala dengan kondisi lingkungan seperti luas lahan terbatas untuk menanam sayuran, fasilitas sanitasi dan kesediaan air bersih yang terbatas karena akses air bersih hanya dari PDAM, latar belakang pendidikan, dan ekonomi yang berkaitan dengan jumlah pendapatan masyarakat yang tidak stabil karena bergantung pada cuaca dan mayoritas penduduk setempat bekerja sebagai tenaga kasar.

3. Elemen Pesan : Khalayak atau 92 Jurnal Public Corner Fisip Universitas Wiraraja masyarakat pesisir dari tiga desa masuk dalam ketgori masyarakat yang cukup menerima informasi kesehatan khusunya Gerakanmasyarakat sehat di masa pandemi melalui komunikasi face to face dan televisi. Adapun pesan yang diterima khsusnya terkait dengan Germas belum mampu sepenuhnya dimengerti jika pesan yang disampaikan memuat istilah-istilah kesehatan.

4. Elemen Media

Berdasarkan hasil pengumpulan data menunjukkan bahwa masayarakat dari desa Marengan laok, Karanganyar, dan Pinggir papas lebih banyak mengetahui informasi kesehatan seperti gerakan masyarakat sehat khusunya di masa pandemi melalui televisi seperti iklan dan berita nasional, acara kemasyarakat seperti arisan, pengajian atau kompolan (perkumpulan kelompok) secara tatap muka, dan yang terakhir melalui media 
sosial seperti youtube.

5. Elemen Efek: Pesan pesan komunikasi kesehatan khusunya pesan Gerakan Masyarakat Sehat belum sampai pada perubahan perilaku hanya sampai pada tahapan menambah wawasan atau pengetahuan si komunikan.

\section{DAFTAR PUSTAKA}

Abadi, T. W., \& Mahendrawati, I. K. (2012). PENERTIBAN VERSUS PENGGUSURAN: STRATEGI KOMUNIKASI DAN PARTISIPASI PEMBANGUNAN (Studi Kasus di Stren Kali Jagir Wonokromo-Surabaya). Scriptura, $3(2)$, 112-128. https://doi.org/10.9744/scriptura.3. 2.112-128

Amanah, S. (2010). Peran Komunikasi Pembangunan dalam Pemberdayaan Masyarakat Pesisir. Jurnal Komunikasi Pembangunan, $8(1)$ 245896. https://doi.org/10.29244/jurnalkmp. 8.1.\%p

BPS. (2018). Sumenep Dalam Angka.

Jhon W Creswell. (2017a). Research Desain Pendekatan Kualitatif, Kuantitatif, dan Mixed. Pustaka Belajar Yogyakarta.

Jhon W Creswell. (2017b). Research Desain Pendekatan Kualitatif, 93 Jurnal Public Corner Fisip Universitas Wiraraja
Kuantitatif, dan Mixed. PustakaBelajar Yogyakarta. Kemenkes RI. (2020). PokokPokok Renstra Kemenkes 2020-2024. Pokja Renstra Kemenkes 2020- 2024, 140.

Rahmanto, A. D., \& Suwandi, A. (2019). PERENCANAAN MCK KOMUNAL BERBASIS

MASYARAKAT DI DESA PINGIRPAPAS

KECAMATAN

KALIANGET

KABUPATEN

SUMENEP. Jurnal Ilmiah MITSU, 7(2), 8-16.

Sayuti. (2021). PERSEPSI

MASYARAKAT DESA PINGGIRPAPAS

KECAMATAN

KALIANGET

KABUPATEN SUMENEP TERHADAP PENGGUNAAN MCK.

Http://Repository.Wiraraja. Ac.Id/1 408/1/JURNAL\%20suyuti. Pdf, 44(8). https://doi.org/10.108 8/1751$8113 / 44 / 8 / 085201$ Surahmi, A., \& Farid, H. M. 
(2018).

$\begin{array}{lr}\text { DUAMPANUA } & \text { KABUPATEN } \\ \text { PINRANG } & \text { Communication }\end{array}$

Strategy in Encouraging People'

$s$ Participation toward

Development in Duampanua

Subdistrict , Pinrang Regency

Pembangunan merupakan suatu

proses pembaharuan yang

kontinyu dan terus Usaha

pembaharuan untuk mendapa.

$7(2), 232-239$.

Wijaya, I. S. (2015). Perencanaan Dan

Strategi Komunikasi Dalam

Kegiatan Pembangunan. Lentera, 17(1), 53-61.

Yuliastina, R. (2020). Abstrak. Edisi, $V(\mathrm{Dd})$.

Zainal, A. G., \& Sarwoprasodjo, S. (2018).

Strategi Komunikasi Politik

Pemerintahan Daerah dalam

Meningkatkan Partisipasi

Masyarakat Pedesaan (Studi

Program "Bupati Ronda" di

Kabupaten Lampung Tengah).

Journal of Communication

Studies, 3(1), 54-66. 